\title{
Methotrexate Effects at High Doses in the Progression of Inflam- matory Periapical Lesions in a Murine Model: Histological and Imaginological Analysis
}

\author{
Silvana Freitas de Souza Leão ${ }^{1^{*}}$ and Danyel Elias da Cruz Perez ${ }^{2}$ \\ ${ }^{1}$ PhD in Dentistry (Integrated Clinic), Federal University of Pernambuco, Brazil \\ ${ }^{2}$ Adjunct Professor, Oral Pathology Section, Brazil
}

*Corresponding author: Silvana Freitas de Souza Leão, PhD in Dentistry (Integrated Clinic), Federal University of Pernambuco, UFPE, Recife, PE, Brazil

\begin{abstract}
Introduction: The aim of this study was to determine the effects of high dose methotrexate in PL induced in rats molars and periapical region.

Methods: It was used 35 male Wistar rats. To induce PL, the pulps of first mandibular molars were exposed using a $1 / 2$ round bur on a high-speed handpiece. It was expected 30 days. Then, 7 groups were formed with 5 animals in each one. G1: No induction of periapical lesions but with weekly intraperitoneal administration (WIPA) of saline solution $(\mathrm{NaCl} 0.9 \%)$ for 2 weeks and sacrifice after 2 days of last WIPA. The groups G2, G3 and G4 suffered periapical induction and WIPA of saline solution for 2 weeks being sacrificed 2.4 and 7 days respectively. The groups G5, G6 and G7 suffered periapical induction and WIPA of methotrexate (12 $\mathrm{mg} / \mathrm{kg} /$ week) for 2 weeks, being sacrificed 2, 4 and 7 days respectively. CBCT was performed to measure the size of $\mathrm{PL}$. A histomorphological analysis was also performed to determine the intensity of the inflammatory infiltrate and the presence of periapical bone resorption. Statistical analyzes used were ANOVA and Kruskall-Wallis test.
\end{abstract}

Results: The size of periapical lesions in control and methotrexate groups showed no statistically significant difference $(p=0.2)$. PL were composed by chronic inflammatory reaction ranging from mild to moderate, predominantly of lymphocytes.

Conclusion: According to the data obtained, in the presence of persistent PL associated with the root canal, treatment with high doses of MTX did not influence the progression of these lesions.

\section{Keywords}

Periapical lesions, Methotrexate, Rats

\section{Introduction}

Treatment for cancer patients can cause significant side effects in the maxillofacial region. The type and intensity of side effects will depend on the mechanism of action of the drugs used. Among these drugs, there are those that cause predominantly cytotoxic acute effects, such as methotrexate.

Methotrexate (MTX), 4-amino-N10-methyl pteroylglutamic acid, a synthetic drug also known as amethopterin, is an antimetabolite that is structurally similar to folic acid. MTX interferes with the synthesis and repair of DNA during cell replication and has anti-inflammatory and antineoplastic properties [1-3]. This potent anti-neoplastic agent used to treat leukemia, osteosarcoma and some types of carcinoma, causes a significant side effects, such as leucopenia [4,5].

Systemic conditions may admittedly influence the development of odontogenic inflammatory lesions, including chronic periapical lesions that are of endodontic origin. Similarly, these odontogenic inflammatory lesions may also influence systemic diseases, sometimes constituting risk factors for systemic complications [6-10]. Although chemotherapy offers benefits, it may arises direct damages and indirect due to immunosuppression induced by therapy $[11,12]$. Chemotherapy may cause serious side effects, from oral mucositis caused by the direct action of the drug in the epithelial cells of the mucous lining up to septicemia due to significant drug-in- 
duced leucopenia [13].

In recent years, various studies have shown that localized inflammation in the oral cavity is associated with increased levels of systemic disease markers $[6,7,14]$. Some previous investigations have shown the impact of diabetes and cardiovascular diseases on periapical healing, probably due triglyceride levels and free radical production, respectively [6-8]. Some studies that used immunossupressive drugs had an inhibitory effect on the development of the periapical lesions [14-18]. More recently, it was demonstrated that epigallocatechin gallate, an active ingredient contained in green tea, displayed protective effects in a rat model of apical periodontitis in vivo [19].

There are few studies evaluating patients with chronic periapical lesions that will undergo chemotherapy for malignancy [20-24]. Thus, the objective of this study was to evaluate in vivo the effects of methotrexate in the onset and progression of chronic periapical lesions induced in the lower first molars of rats.

\section{Methods}

The Local Ethics Committee on Animal Use (protocol \# 23076.042032/2011-46) approved this study. Thirtyfive male rats (Rattus norvegicus, albinus Wistar) were used, which weighted between 220 and 250 grams. The animals were housed in a vivarium where they received a standard rat diet (Presence Ratos e Camundongos, Presence, Paulinea, SP, Brazil) and water ad libitum. They were kept in a room with a temperature of $23 \pm 2$ ${ }^{\circ} \mathrm{C}$ and light/dark cycle of 12:12 hours.

Previously to experimental procedures, the animals were anesthetized with ketamine hydrochloride $1 \mathrm{~mL} /$ kg (SESP, Vetbrands Animal Health Division, Jacarei, São Paulo, Brazil) associated with xylazine $0.5 \mathrm{~mL} / \mathrm{kg}$ (Bayer Brazil, Beford Purple, Rio de Janeiro, Brazil) intramus- cularly. In order to induce periapical lesions in animals, the pulps of the first bilateral molars were exposed on the occlusal surface using carbide bur $1 / 2$ coupled to high speed hand piece. The dental pulps remained exposed for 30 days in the oral cavity, according to the author's methodology. After induction of periapical lesions, the animals were randomly distributed into 7 groups according to drug administration and analysis time. The sequence descriptions are summarized in Table 1 . The animals of experimental group were treated with methotrexate (Lexato, Laboratories Pierre Fabre do Brasil LTDA, Rio de Janeiro, Brazil) using a dosage of $12 \mathrm{mg} /$ $\mathrm{Kg} /$ week, for 2 weeks, administered intraperitoneally, while control groups were treated with saline solution $(\mathrm{NaCl} 0.9 \%)$ also administered intraperitoneally.

After the period of analysis established, the animals were euthanized by anesthetic overdose with ketamine hydrochloride and xylazine. The mandibles were dissected and placed into plastic recipient containing $10 \%$ formaldehyde solution. In these recipients, the specimens were submitted to cone-beam computed tomography (CBCT) (i-CAT Next Generation, Imaging Sciences International, Hatfield, PA), operating at $120 \mathrm{kV}$ and 3.8 $\mathrm{mA}$, using a protocol with voxel size of $0.2 \mathrm{~mm}$ and an exposure time of 26 seconds. Then, images were reconstructed and evaluated using the XORAN software (Xoran CAT version 2.0.21, Xoran Technologies, Ann Arbor Mich, EUA). A specialist in Oral Radiology with experience in the method used analyzed the images in multiplanar reconstructions (axial, sagittal and coronal). The measurement was taking in the larger diameter of the lesions associated with the mesial root of the mandibular first molar in each specimen analyzed, using sagittal views with $0.25 \mathrm{~mm}$ of thickness. A single analysis was performed and the evaluator was blinded with respect to groups analyzed. It was used a 22" flat screen monitor (Dell Precision 390 ${ }^{\mathrm{Tm}}$, Dell Inc., Round Rock, Texas,

Table 1: Control and experimental groups used in the study.

\begin{tabular}{|l|l|l|}
\hline Groups & N & Experimental procedures \\
\hline G1 & 5 & $\begin{array}{l}\text { Negative control-without periapical lesion. Saline solution administered intraperitoneally (IP) one time a } \\
\text { week for 2 weeks. Analysis after the last dose. }\end{array}$ \\
\hline $\begin{array}{l}\text { G2 } \\
\text { (PL2) }\end{array}$ & 5 & $\begin{array}{l}\text { Positive control-periapical lesion induction, Saline solution administered IP one time a week for 2 weeks } \\
\text { and analysis after 2 days after last dose. }\end{array}$ \\
\hline $\begin{array}{l}\text { G3 } \\
\text { (PL4) }\end{array}$ & 5 & $\begin{array}{l}\text { Positive control-periapical lesion induction, Saline solution administered IP one time a week for 2 weeks } \\
\text { and analysis after 4 days after last dose. }\end{array}$ \\
\hline $\begin{array}{l}\text { G4 } \\
\text { (PL7) }\end{array}$ & 5 & $\begin{array}{l}\text { Positive control-periapical lesion induction, Saline solution administered IP one time a week for 2 weeks } \\
\text { and analysis after 7 days after last dose. }\end{array}$ \\
\hline $\begin{array}{l}\text { G5 } \\
\text { PL-MTX-2 }\end{array}$ & 5 & $\begin{array}{l}\text { Periapical lesion induction, 12 } \mathrm{mg} / \mathrm{Kg} \text { of methotrexate administered one time a week for 2 weeks and } \\
\text { analysis after 2 days after last dose. }\end{array}$ \\
\hline $\begin{array}{l}\text { G6 } \\
\text { PL-MTX-4 }\end{array}$ & 5 & $\begin{array}{l}\text { Periapical lesion induction, 12 } \mathrm{mg} / \mathrm{Kg} \text { of methotrexate administered one time a week for } 2 \text { weeks and } \\
\text { analysis after 4 days after last dose. }\end{array}$ \\
\hline $\begin{array}{l}\text { G7 } \\
\text { PL-MTX-7 }\end{array}$ & 5 & $\begin{array}{l}\text { Periapical lesion induction, 12 } \mathrm{mg} / \mathrm{Kg} \text { of methotrexate administered one time a week for } 2 \text { weeks and } \\
\text { analysis after 7 days after last dose. }\end{array}$ \\
\hline
\end{tabular}


EUA). Images density and contrast were accordingly adjusted to help the observer.

After the image analysis, the jaws were decalcified in $5.0 \%$ aqueous nitric acid $\left(\mathrm{HNO}_{3}\right)$ for 48 hours. Then, a histological conventional procedure was performed. Histological sections of $5 \mu \mathrm{m}$ were obtained from paraffin blocks and stained with hematoxylin-eosin (HE). In order to determine the intensity of the inflammatory infiltrates (acute or chronic type), a histological analysis was carried out. The inflammatory reaction in the periapical lesions was classified as slight (scarce or focal inflammatory reaction), moderate (moderate amount of inflammatory cells) or severe (diffuse inflammatory reaction). During analysis, the evaluator was also blinded with respect to group studied.

The histological and imaginological data were analyzed by descriptive statistic. The imaginological data that showed uniform distribution were analyzed by ANOVA and for those that showed non-homogeneous distribution, the nonparametric Kruskal-Wallis test was used, considering a significance of $5 \%$. Statistical calculations were performed using SAS 9.2 software.

\section{Results}

In the imaging analysis, the periapical lesions were evident in the periapical area of right mandibular first molars in all groups and were identified by CBCT (Figure 1 and Figure 2).

The size of periapical lesions in control and methotrexate groups were measured and showed no statistically significant difference ( $p=0.2$ ). The measures observed in imaging analysis are shown in Table 2.

In the histological analysis, the periapical lesions in all specimens were composed of fibrous connective tissue infiltrated by chronic inflammatory reaction, formed predominantly for lymphocytes. Periapical lesions were both areas with mild chronic inflammation as areas with inflammation of moderate intensity. Specimens of

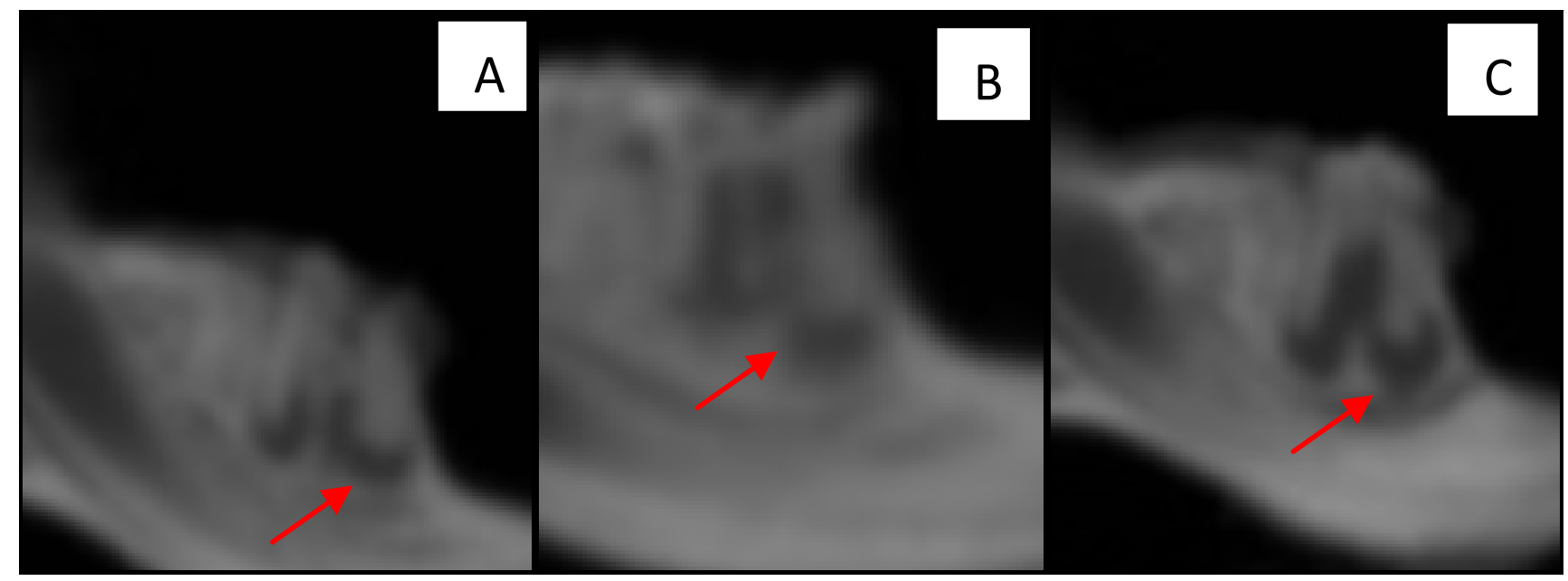

Figure 1: Sagital views of mandibular first rat molars. A) An arrow indicate a periapical lesion in a specimen of $\mathrm{G} 2(1.7 \mathrm{~mm})$; B) An arrow indicate a periapical lesion in a specimen of $\mathrm{G} 3(1.5 \mathrm{~mm})$; C) An arrow indicate a periapical lesion in a specimen of G4 (1.65 mm).

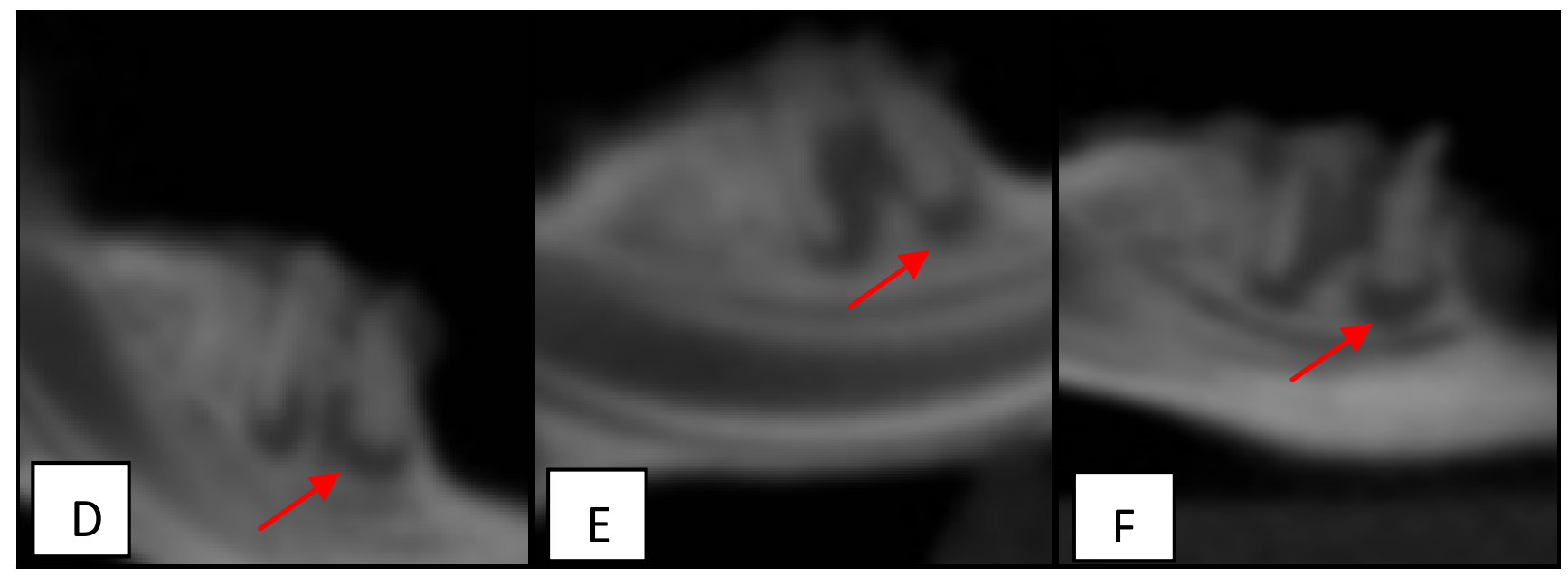

Figure 2: Sagital views of mandibular first rat molars. D) An arrow indicate a periapical lesion in a specimen of $\mathrm{G} 5$ (1.5 mm); E) An arrow indicate a periapical lesion in a specimen of G6 (1.6 mm); F) An arrow indicate a periapical lesion in a specimen of $\mathrm{G} 7(1.46 \mathrm{~mm})$. 
Table 2: Mean size of the periapical lesions and analysis of matching control and experimental groups.

\begin{tabular}{|l|l|l|l|}
\hline Groups & Histological analysis & $\begin{array}{l}\text { Mean size in mm } \\
\text { (Minimum-maximum) }\end{array}$ & P* value \\
\hline G1 & No inflammatory reaction & No lesion & 0.2 \\
\hline G2 & Chronic inflammation mild & $1.7 \mathrm{~mm}(1.3-1.9)$ \\
\hline G3 & Chronic inflammation mild & $1.5 \mathrm{~mm}(1.2-1.6)$ \\
\hline G4 & Chronic inflammation moderate & $1.65 \mathrm{~mm}(1.3-1.8)$ \\
\hline G5 & Chronic inflammation mild & $1.5 \mathrm{~mm}(1.2-1.7)$ \\
\hline G6 & Chronic inflammation mild & $1.6 \mathrm{~mm}(1.4-1.7)$ \\
\hline G7 & Chronic inflammation mild & $1.46(1.1-1.5)$ & \\
\hline
\end{tabular}

* $\mathrm{p}$ value resulting from the comparison between groups.

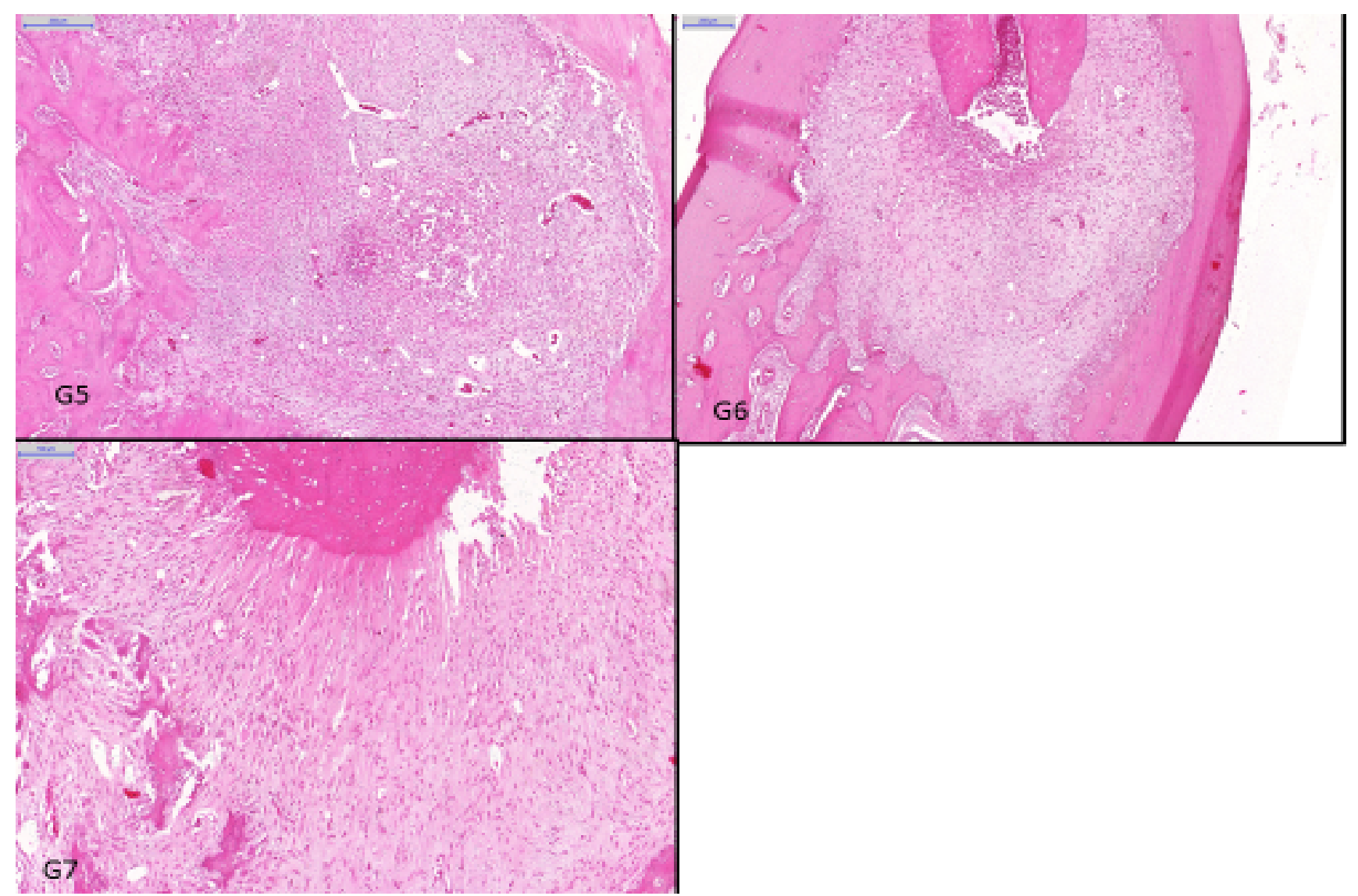

Figure 3: Histological findings in periapical regions. Groups: G5 showed mild inflammatory infiltration (HE, original magnification $\times 200 \mu \mathrm{m}$ ); G6 showed mild inflammatory infiltration (HE, original magnification $\times 200 \mu \mathrm{m}$ ); G7 showed mild inflammatory infiltration (HE, original magnification $\times 100 \mu \mathrm{m})$.

Group G7 (Figure 3) had mild inflammatory reaction in all specimens, but there was no significant difference between groups ( $p=0.62)$, (Figure 3 and Figure 4).

\section{Discussion}

There are few studies that evaluate patients with chronic periapical lesions that will undergo anti neoplastic therapy. The presence of these lesions may be a risk factor for the development of acute infection during therapy. Thus, it becomes necessary to know methotrexate role in the progression of the periapical lesion. In addition, there are few studies assessing the possible effects of methotrexate in the evolution of chronic periapical pathologies in animals $[4,5,7,8,10]$.
In order to generate evidence for protocols in dental treatment, this study observed the behavior of periapical lesions in rats treated with methotrexate (MTX). This drug was chosen for the purpose of inhibiting the growth of lymphocytes subpopulations $[5,16]$. Other immunosuppressive drugs have also been tested in animal models by many researchers, to simulate radiographic and histological features of the immune response in the development of periapical lesions.

Lopes, et al. [25] showed a reduction of circling lymphocytes in periapical lesions of immunosupressed groups treated with cyclophosphamide at daily dosages of 10 $\mathrm{mg} / \mathrm{Kg}$, and Watermann, et al. [17] also reduced peri- 


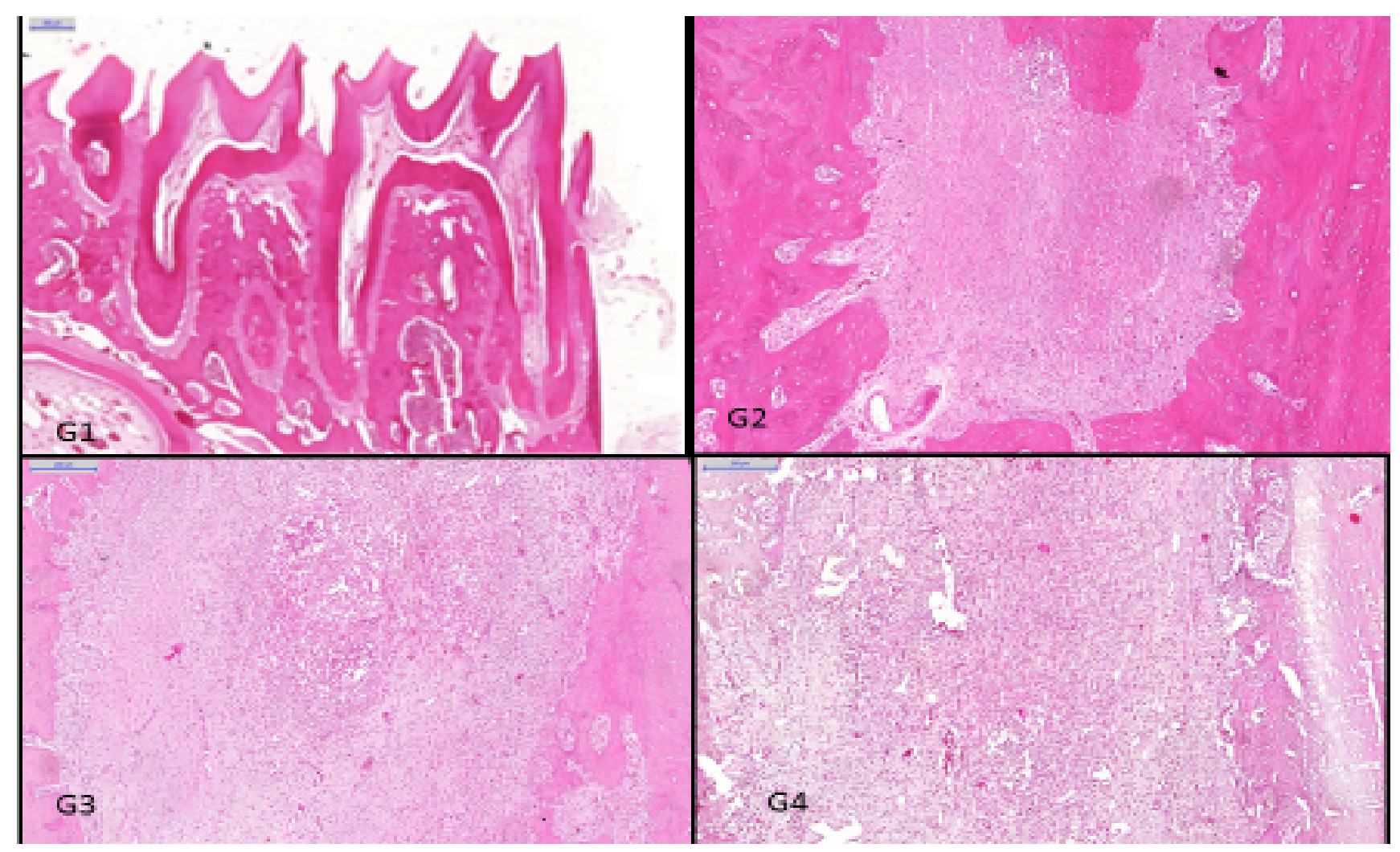

Figure 4: Histological findings in periapical regions. Groups: G1 showed no inflammatory infiltration (HE, original magnification $\times 500 \mu \mathrm{m}$ ); G2 showed mild inflammatory infiltration (HE, original magnification $\times 200 \mu \mathrm{m}$ ); G3 showed mild inflammatory infiltration (HE, original magnification $\times 200 \mu \mathrm{m}$ ); G4 showed moderate inflammatory infiltration).

apical lesions in rats, using a weekly dosage of $50 \mathrm{mg} /$ $\mathrm{Kg}$ of cyclophosphamide. This experiment used dosages equivalent to those used in treatment of human lymphomas or leukemia. On the other hand, Metzger, et al. [14] tested dexamethasone with $0.5 \mathrm{mg} / \mathrm{Kg}$ in periapical lesions every third day during 14 days and 21 days. This drug had an inhibitory effect on the development of the periapical lesions when compared with control groups. Moreover, Kawahara, et al. [18] showed a reduction of T lymphocytes cells in groups treated with cyclosporine, at daily dosages of 5,10 and $20 \mathrm{mg} / \mathrm{Kg} /$ day for 4 weeks. In the actual conditions of this experiment studied, the methotrexate, an immunosuppressive drug, applied at dosages of $12 \mathrm{mg} / \mathrm{Kg}$ once per week during 2 weeks, did not show an inhibitory effect of periapical lesions in both experimental and control groups.

Methotrexate has been administered orally or intravenously, in daily clinical treatment. In the present study, it was administered intraperitoneally, similar to other published reports $[5,16,26,27]$. Even though that intraperitoneal administration results in a lower plasmatic concentration of the drug, this technique was chosen because it is safer and easier to apply in small animals. The dosages used in experimental studies vary widely. Willoughby and Giroud [16] and Rylander [26] administered a dose of $2.5 \mathrm{mg} / \mathrm{kg}$. Yamasaki, et al. [5] used a dose of $1.0 \mathrm{mg} / \mathrm{Kg}$, whereas Nakamura, et al. [4] used a dose of $7.5 \mathrm{mg} / \mathrm{kg}$ of methotrexate in rats. In this study, we used the dosage of $12 \mathrm{mg} / \mathrm{kg} /$ week per 2 weeks. Although it can be considered a high dose, its use has been safety demonstrated in these previous studies and it was chosen to increase the probability of leukopenia in the studied animals.

In the present study, periapical lesions were induced by pulp mechanical exposure, according to protocols used in the literature $[6,4,28-30]$. Studies have showed that after pulp exposure in rats, pulpal necrosis and periapical lesions extended maximally between 7 and 14 days [31]. Morimoto, et al. [32], also observed that periapical inflammation, developed from 7 to 21 days, subsided after 28 days and subsequently decreased at 42 days. This is in agreement with the findings of a previous study that observed pulp necrosis in the experimental period of 15 and 30 days [33]. Osteoclasts in periapical lesions could be found at day 2 and the peak number of these cells was reached at day 14 . In these studies, it was also observed that increasing amounts of inflammatory infiltration and alveolar bone resorption occurred in the periapical region from day 7 to day 14 [34,35]. Between 0 and 20 days occurred a period of lesion expansion and bone destruction [36]. Based on these studies, the pulps were exposed in the oral cavity for a period of 30 days to induce periapical lesion.

According to the methodology of this study, we expected a period of 30 days, and applied the methotrexate (MTX) in a dosage of $12 \mathrm{mg} / \mathrm{Kg} /$ week per 2 weeks in the intervals between the $2^{\text {nd }}$, the $4^{\text {th }}$ and the $7^{\text {th }}$ days, but this drug did not promote greater inhibition in the 
progress of the periapical bone resorption after pulpal exposure. This is not in agreement with the studies of Yamasaki, et al. [5] which analyzed the progression of periapical lesions, after pulpal exposure in the intervals between 2, 4 and 6 weeks. Our study also is not in agreement with Nakamura, et al. [4] that observed periapical lesions after 2, 4 and 7 days after pulpal exposure. Yamasaki, et al. [5] showed that when the experimental group received MTX 3 times a week before pulpal exposure, methotrexate-induced neutropenia inhibited the development of periapical lesions. After 6 weeks, the histological findings showed its periapical inflammation in experimental groups weaker than that of the control group and in the group that received MTX after pulpal exposure. The neutrophil count statistically decreased at 2 weeks after the first injection of methotrexate. Nakamura, et al. [4] showed that the area of pulpal necrosis in the experimental group was statistically larger than that of the control group, although, both groups showed no difference in the size of the periodontal ligament area. This is probably because the histometrical results showed that the neutropenia reduced the extent of abscess formation after pulpal exposure and increased the area of pulpal necrosis due to the poorly opposed of the pulpal tissue. Rylander [26] demonstrated that the number of leukocytes that infiltrated an implanted chamber in rats, decreased if the animals were injected with methotrexate. It is well known that the neutrophils infiltrate in an early stage of inflammation. This fact occurred with the studies of Yamasaki, et al. [5] and Nakamura, et al. [4] and probably it had occurred in the present study.

The histological analysis, in the present study, are not in consistence with these previous studies $[5,28,30]$ since these authors analyzed the progression of periapical lesions between the $7^{\text {th }}$ and $14^{\text {th }}$ until the $28^{\text {th }}$ day after pulpal exposure. Although, in this study, the pulp exposure of the experimental group G7, had been 7 days, this group showed mild inflammatory reaction in all specimens. There was no significant difference between group $\mathrm{G} 7$ and the groups G2, G3, G4, G5, G6 ( $p=$ 0.62) (Table 1).

Yamasaki, et al. [31] corroborated with our findings because in their histological studies, in pulpal and periapical tissues in rats, it was observed that at 56 days, necrosis remained in the periapical tissue but, inflammatory cell infiltration decreased in the periapical tissue and fibrous tissue proliferation increased as well as the alveolar bone and apical root resorption was still found.

The periapical lesions size in this study were measured by micro-computed tomography scanning. Some authors have assessed the apices of the molar roots of mouse mandibles by other radiographic techniques to observe the growth of periapical lesions [15,31,33]. These authors have observed radiographically that periapical lesion extended maximally between 7 and 14 days $[28,15]$. Teixeira, et al. [33] confirmed radiographically the presence and intensity of bone resorption observed by the histological study. These authors observed bone resorption at 2, 15 and 30 days, and observed in the 30-day experimental period a large area of resorption, but a smaller number of osteoclasts were present $[15,30,31,37]$. The amount of periapical bone was minimal, and it was replaced by inflammatory tissue. In the present study, the size of periapical lesions were similar among groups (Table 2). This probably occurred because after 42 days, there were no further expansion in the periapical lesions [32]. Moreover, the methotrexate did not inhibit the growth of periapical lesions as demonstrated in the experimental conditions of this study $(p=0.2)$. Depending on the dosage, frequency and intensity with which it is applied, methotrexate can provoke some degree of systemic side effects. In Dentistry, further studies are necessary for the provision of safe procedures including the endodontic treatment of patients with chronic periapical lesions and will undergo anti-neoplastic therapy.

\section{Conclusion}

According to the data obtained, high doses of methotrexate did not influence the population of inflammatory cells and the size of the chronic periapical lesions in rats.

\section{Acknowledgements}

The authors are thankful to the (FACEPE) SUPPORT FOUNDATION SCIENCE AND TECHNOLOGY OF PERNAMBUCO STATE for the financial support granted to this work.

\section{References}

1. Cronstein BN (1996) Molecular therapeutics. Methotrexate and its mechanism of action. Arthritis Rheum 39: 19511960.

2. May KP, West SG, McDermott MT, Huffer WE (1994) The effect of low-dose methotrexate on bone metabolism and histomorphometry in rats. Arthritis Rheum 37: 201-206.

3. Kalantzis A, Marshman Z, Falconer DT, Morgan PR, Odell EW (2005) Oral effects of low-dose methotrexate treatment. Oral Surg Oral Med Oral Pathol Oral Radiol Endod 100: $52-62$.

4. Nakamura K, Yamasaki M, Nishigaki N, Iwama A, Imaizumi I, et al. (2002) Effect of methotrexate-induced neutropenia on pulpal inflammation in rats. J Endod 28: 287-290.

5. Yamasaki M, Kumazawa M, Koshaka T, Nakamura $H$ (1994) Effect of methotrexate induced neutropenia on rat periapical lesion. Oral surg Oral Med Oral Pathol 77: 655661.

6. Wolle CFB, de Aguiar Zollmann L, Etges A, Vitalis GS, Leite CE, et al. (2012) Effects of the antioxidant agent tempol on periapical lesions in rats with doxorubicin-induced cardiomyopathy. J Endod 38: 191-195.

7. Cintra LT, da Silva Facundo AC, Azuma MM, Sumida DH, Astolphi RD, et al. (2012) Pulpal and periodontal diseases increase triglyceride levels in diabetic rats. Clin Oral Investig 


\section{7: 1595-1599.}

8. Marotta PS, Fontes TV, Armada L, Lima KC, Rôças IN, et al. (2012) Type 2 diabetes mellitus and the prevalence of apical periodontitis and endodontic treatment in an adult Brazilian population. J Endod 38: 297-300.

9. Cotti E, Schirru E, Acquash E, Usai P (2014) An overview on biologic medications and their possible role in apical periodontitis. J Endod 40: 1902-1911.

10. Astolphi RD, Curbete MM, Chiba FY, Cintra LT, Ervolino E, et al. (2015) Periapical lesions decrease insulin signiling in rat skeletal muscle. J Endod 41: 1305-1310.

11. Peterson DE (1990) Pretreatment strategies for infection prevention in chemotherapy patients. NCI Monogr 9: 61-71.

12. Vissink A, Jansma J, Spijkervet FK, Burlage FR, Coppes RP (2003) Oral sequelae of head and neck radiotherapy. Crit Rev Oral Biol Med 14: 199-212.

13. Peterson DE (1992) Oral toxicity of chemotherapeutic agents. Semin Oncol 19: 478-491.

14. Metzger Z, Klein H, Klein A, Tagger M (2002) Periapical lesion development in rats inhibited by dexamethasone. $J$ Endod 28: 643-645.

15. Yu SM, Stashenko P (1987) Identification of inflammatory cells in developing rat periapical lesions. J Endod 13: 535540.

16. Willoughby DA, Giroud JP (1969) The role of polymorphonuclear leucocytes in acute inflammation in agranulocytic rats. J Pathol 98: 53-60.

17. Waterman PA Jr, Torabinejad M, McMillan PJ, Kettering JD (1998) Development of periradicular lesions in immunosuppressed rats. Oral Surg Oral Med Oral Pathol Oral Radiol Endod 85: 720-725.

18. Kawahara T, Murakami S, Noiri Y, Ehara A, Takemura N, et al. (2004) Effects of cyclosporin-a-induced immunosuppression on periapical lesions in rats. J Dent Res 83: 683687.

19. Lee YL, Hong CY, Kok SH, Hou KL, Lin YT, et al. (2009) An extract of green tea, epigalocatechin-3-gallate, reduces periapical lesions by inhibiting cysteine-rich 61 expression in osteoblasts. J Endod 35: 206-211.

20. Toljanic JA, Bedard JF, Larson RA, Fox JP (1999) A prospective pilot study to evaluate a new dental assessment and treatment paradigm for patients scheduled to undergo intensive chemotherapy for cancer. Cancer 85: 1843-1848.

21. Greenberg MS, Cohen SG, McKitrick JC, Cassileth PA (1982) The oral flora as a source of septicemia in patients with acute leukemia. Oral Surg Oral Med Oral Pathol 53: 32-36.

22. Overholser CD, Peterson DE, Williams LT, Schimpff SC (1982) Periodontal infection in patients with acute nonlymphocytic leukemia: Prevalence of acute exacerbations. Arch Intern Med 142: 551-554.
23. Dreizen S, McCredie KB, Bodey GP, Keating MJ (1986) Quantitative analysis of the oral complication of antileukemia chemotherapy. Oral Surg Oral Med Oral Pathol 62: 650653.

24. Sonis ST, Woods PD, White BA (1990) Pretreatment oral assessment. NCl Monogr 9: 29-32.

25. Lopes MA, Spolidorio LC, Line SR, Almeida OP (1997) Pulpal lesions in normal and cyclosporine-A treated rats. $J$ endod 23: 52-53.

26. Rylander H (1974) Acute inflammation and granulation tissue formation in neutropenic rats. Odontol Revy 25: 147156.

27. Zeller JM, Cunera MB, Gudewicz PW (1984) Effects of high dose methotrexate on rat alveolar and inflammatory machrophage populations. Inflammation 8: 231-239.

28. Kakehashi S, Stanley HR, Fitzgerald RJ (1965) The effects of surgical exposures of dental pulps in germ free and conventional laboratory rats. Oral Surg Oral Med Oral Pathol 20: 340-349.

29. Tagger M, Massler M (1975) Periapical tissue reactions after pulp exposure in rat molars. Oral Surg Oral Med Oral Pathol 39: 304-316.

30. Stashenko P, Wang CY, Tani-Ishi N, Yu SM (1994) Pathogenesis of induced rat periapical lesions. Oral Surg Oral Med Oral Pathol 78: 494-502.

31. Yamasaki M, Kumazawa M, Koshaka T, Nakamura $H$, Kameyama Y (1994) Pulpal and periapical tissue reactions after experimental pulpal exposure in rats. J Endod 20: 1317.

32. Morimoto T, Yamasaki M, Nakata K, Tsuji M, Nakamura $H$ (2008) The expression of macrophage and neutrophil elastases in rat periapical lesions. J Endod 34: 1072-1076.

33. Teixeira RC, Rubira CMF, Assis GF, Lauris JRP, Cestari TM, et al. (2011) Radiological and histophatological evaluation of experimentally induced periapical lesion in rats. J Appl Oral Sci 19: 500-504.

34. Zhang X, Peng B (2005) Immunolocalization of receptor activator of NF kappa B ligand in rat periapical lesions. J Endod 31: 574-577.

35. Yang L, Zhang C, Peng B (2009) Immunolocalization of tumor necrosis factor receptor-associated factor 6 in rat periapical lesions. J Endod 35: 834-837.

36. Stashenko P, Yu SM, Wang CY (1992) Kinetics of immune cell and bone resorptive responses to endodontic infections. J Endod 18: 422-426.

37. Tanomaru-Filho M, Jorge EG, Duarte MA, Gonçalves M, Guerreiro-Tanomaru JM (2009) Comparative radiographic and histological analysis of periapical lesion development. Oral Surg Oral Med Oral Pathol Oral Radiol Endod 107: 442-447. 